\title{
Factors affecting direct and indirect benefit exchange in the social media-based learning experience
}

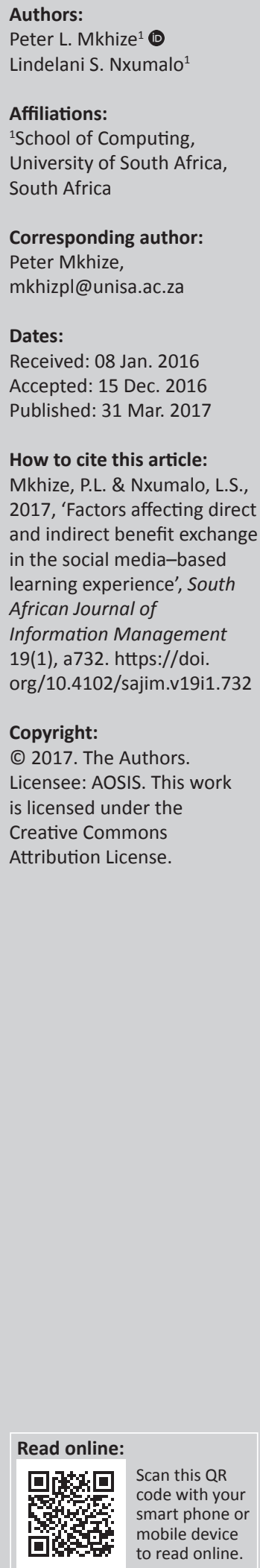

Background: Social media platforms are thriving on the co-creation of content, usually socially orientated content about the social interests of participants. There is also a growing trend of social media application in the human resources and marketing for business purposes. This study investigates factors that have an impact on the sharing of knowledge on social media platforms, particularly students at an Open Distance Learning (ODL) institution.

Objective: This study evaluates the difference between direct and indirect benefit exchange expected by students when sharing knowledge.

Method: Random and theoretical sampling were used to select the sample in this study from the population. A literature-informed questionnaire was used as an instrument to collect data from a selected sample of 315 students from the School of Computing at the University of South Africa.

Results: A test of association was conducted to evaluate correlations, which revealed that only reputation and social language correlate with direct and indirect benefit exchange. Results indicate that there is a significant mean difference between direct and indirect benefit exchange and that issues concerning social identity and trust should be taken into account when developing social media instructional design.

Conclusion: In this study, a survey was used to test the hypothesis. The authors concluded that instructional designer can design teaching and learning experience in the social media platform by catering for both direct and indirect benefit knowledge exchange. The results of the study further confirmed that some students share knowledge with the expectation of direct exchange benefit and, meanwhile, expect indirect exchange benefit.

\section{Introduction}

The University of South Africa (UNISA) is an Open Distance Learning (ODL) institution of higher learning, where students have an option to share knowledge either directly or indirectly by means of social media, in this case Wikis, microblog and discussion forum. It is not yet clear what leads to a student's willingness to directly or indirectly exchange knowledge on the social network platform. Many factors may influence a student's decision to directly or indirectly share knowledge with their fellow students. This study investigates four factors that have an influence on students who are sharing knowledge: social trust, social identity, reputation and social language.

This article is structured as follows: first, the background for the study is discussed, followed by an explanation of the problem statement to be addressed, an explication of the research objectives and questions guiding the process for this study, a discussion on existing literature about the factors that influence students' decision to share knowledge directly or indirectly, the hypotheses and theoretical framework of the study, an explanation of the research methodology used to test each hypothesis, a discussion of the results and contribution of the study, and conclusion.

\section{Background to the study}

This study focuses on the investigation of factors that influence students' decision to share knowledge directly or indirectly with their fellow students in the ODL environment, using social media platforms. This study is based on students who are registered with the UNISA. This university is an ODL institution with an open access policy, which means that it gives students, who would otherwise not have been able to study because of a variety of socio-economic issues, access to tertiary education. 
The student demographics in UNISA has changed over the years from employed adults to young school leavers who register at a tertiary institution for the first time. The majority of the younger students spend time on social media platforms such as Facebook to share information that appeals to their personal interests (World Wide Worx 2013). As far as the researchers are aware, there is no study that focuses on the investigation of social factors that have an influence on the educational use of social media in developing countries, specifically in the Southern African Development Community (SADC) region. Therefore, the researchers will investigate the impact of social factors, such as reputation, social identity and trust, and shared language in direct and indirect exchange of knowledge with students.

\section{Problem statement}

In the knowledge society, knowledge has become a key resource for many organisations. In line with the argument of Ma and Yu (2010), organisations are becoming increasingly dependent on knowledge as an intangible asset, which is difficult to clone; socially complex; and could be the source of superior performance to sustain competitiveness in the industry. However, knowledge is illusive in a sense that it is linked to the retention of employees and their mobility. Many factors may contribute to a loss of expertise for an organisation - employees who retire, resign, are poached, or are diseased. Some organisations acquire knowledge by poaching the skilled employees of other organisations (Li \& Sheldon 2010).

Sending an employee for a formal education such as a Bachelor's degree or a diploma is usually costly for some organisations. As a result, organisations resort to poaching skilled employees from other organisations. An ODL institution may be an alternative to which employees could be sent, because its model allows students to study from wherever they are at their own pace. The UNISA is the only ODL institution in the country, which by the virtue of its model thrives on Information and Communication Technologies. The university is popular to the country's student population specifically those who are already working, because of its open, collaborative learning environment and its student-centred delivery approach.

The fact that an ODL model thrives on information and communications technology (ICT) could prove to be problematic for an institution that is based in a developing country from where it serves the students. However, it is important to note that social media exposure in South Africa is as good as in the developed countries (World Wide Worx 2013). There has been an increase in the number of users of social media and more and more time is spent on social media platforms. Social media platforms enable collaboration between friends who usually share social knowledge about issues of personal interest. In line with the underlying principle of ODL, which, among others, is about collaboration and openness, the researchers will investigate factors that could influence the direct or indirect sharing of knowledge with fellow students whether or not they are acquaintances or strangers.

It is important to take into account that posting or sharing an idea by using social media could be approached with scepticism as social media platforms like Twitter and Facebook are sometimes used to pillory politicians and celebrities for the opinions they share. This kind of behaviour in the social media space could inhibit or stop students who want to share valuable insights with their fellow students, thereby depriving other students of valuable insights.

When valuable insights are only shared with one partner, the other members of the class do not benefit from the shared insight. It is true that some messages should be directly exchanged with the desired recipient, but in a class situation and for the purpose of collaboration, indirect exchange would even benefit the passive participants.

This study is not based on a specific social media platform, because in class any of the social media platforms can be used depending on the objectives and delivery mode for a specific course. It focuses on social factors that would influence the decision of individual students to post or share their insights on a social platform. Another important point to consider is that any interaction via social media, even if it is for educational purpose, can be accessed by anybody who is linked to one class of members. Therefore, the influence of social trust, reputation, social identity, knowledge exchange and shared language on exchange will be investigated in line with the objectives outlined below.

\section{Research objectives}

The research objectives were:

- To evaluate difference on students decision to share insight directly or indirectly.

- To evaluate the association between reputation, and direct and indirect exchange.

- To evaluate the association between shared language, and direct and indirect exchange.

- To evaluate the association between social identity, and direct and indirect exchange.

- To evaluate the association between social trust, and direct and indirect exchange.

\section{Literature review}

In this section, authors discuss theoretical constructs that enable the researcher to understand dimensions of the research problem. These constructs are used to formulate a theoretical framework that forms the bases of the empirical research processes. A deductive enquiry allows the researcher to extract items of the research instruments based on these constructs. They acknowledge the fact that there are different methods of conducting literature review, for the purpose of this study, literature is used for conceptualisation purpose than chronological development of the concepts or critical discourse. 


\section{Social identity}

Identification can be defined as a process whereby a human being sees himself or herself as one with another human being or a group of people (Nahapiet 1998; Wang \& Noe 2010). Social identification is derived from the concept of group identification, as a result these two terms can be used interchangeably (Tolman 1943). Hogg and Terry (2000) stated that the concept of social identity, which includes the individual's sense of belonging to certain social groups together with some emotional and value of significance to him of this group membership was first introduced by Tajfel (1972).

Social identity can be better explained using the social identity theory (SIT) developed by Tajfel and Turner in 1985. The SIT states that people tend to categorise themselves according to religious affiliation, organisational membership, gender and age (Tajfel \& Turner 1985). One individual might identify himself as youth, because of his age group and another individual might be identified as a girl, while yet another individual might be identified as a young Christian girl. Tajfel \& Turner (1985) stated that it answers the question, 'Who am I?'. Koskinen (2005) argued that identity is contingent on differences between individuals within a social setting, which hinders innovation in organisations because some members may try to protect their set ways of doing things.

Social identity could also be a source of metaphoric boundary that may be impenetrable to allow the sharing of knowledge with external parties. Crane (2012) noted that identity is dynamic and deeply interwoven into social context. According to Chiu, Hsu and Wang (2006), social identity can be looked at individually or from a group perspective. This relates to identity as an individual's sense of belonging to a community, which may constitute a significant barrier to sharing information (Dimofte, Goostein \& Brumbaugh 2015; Hogg \& Terry 2000). However, Liu, Chang and Hu (2010) asserted that identity has an important effect on an individual's intention to share and the quality of knowledge.

In this study, social identity is viewed from the perspective of Kimmerle, Wodzicki and Cress (2008) who asserted that intellectual tasks cannot be executed by a single individual in the global economy. Organisations survive through the collaboration of individuals in such organisations or collaboration with their counterparts in other organisations. Kimmerle et al. (2008) further argued that strong identity with the organisation influences willingness to be supportive towards colleagues and improve levels of motivation. This then influences the attitude and behaviour of employees that are relevant for the organisation (Riketta \& Van Dick 2005).

H1: Social identity has a positive correlation with direct benefit exchange.

H2: Social identity has a positive correlation with indirect benefit exchange.

\section{Reputation}

Individual member's reputation in a social group is evaluated and defined based on the experiences of others (Zhuang, Fong \& Shi 2008). Such experiences are captured in the minds of participants in the knowledge sharing initiative. Even though these evaluations are not formal, they are stored and used as a frame of reference in future engagements with the same person. Mehra, Dixon and Brass (2006) asserted that a good reputation helps in the competitive situation where individuals in the organisation may need to share information and ideas through a friendship bond and trust. Favourable reputation could also put sharing members within the community at ease with one another, which creates an environment that is conducive for sharing tacit knowledge, given its complexity.

It is also important to note that personal honour is a more important determinant of reputation than an individuals' measurable accomplishment with the exception of educational achievements (Redding \& Rowley 2012). Personal accomplishments could be perceived as a source of negative reputation depending on the community values. In some communities, personal wealth could be seen as a weakness to physical materialism, whereas moderation could be viewed as an indication of a strong character. The study of Dench et al (2006) measured the role of reputation in the farming community of traders and found that reputation improves public confidence and customer service. A positive reputation could be a determinant of an individual's trustworthiness in the community; the individual, in turn, becomes a preferred partner in any future interaction.

H3: Good reputation has a positive correlation with direct benefit exchange.

H4: Good reputation has a positive correlation with indirect benefit exchange.

\section{Shared language}

Shared language could provide an instrument to evaluate the benefit of sharing knowledge and facilitate access to the insight of other people (Chiu et al. 2006). This enables engagement in knowledge sharing at multiple levels of the organisation, and the sharing of mutual respect and benefit. $\mathrm{Pi}$, Chou and Liao (2013) asserted that shared language has a positive effect on the sharing of knowledge, where members of the community share a specific vocabulary.

Tsai and Ghoshal (1998) pointed out the importance of shared language to render assistance to members of the community in understanding a common goal. Shared language has an influence on the combination and exchange of intellectual capitals in many different ways (Wang \& Noe 2010). Firstly, shared language enables an individual to interact with other individuals and share information that belongs to them. Secondly, it provides a common conceptual apparatus for evaluating the possible gains of exchange and combination. Finally, it stands for the overlay in information (Chiu et al. 2006). It builds an environment in which individuals understand one another and establish common language in 
their domain (Chiu et al. 2006). Knowledge sharing in the absence of shared language could be chaotic, especially when participants do not have common understanding of shared terms and codes (Pi et al. 2013). In the case of knowledge sharing on social media platforms, participants should have shared language that would enable them to access the intellect of others.

H5: Shared language has a positive correlation with direct benefit exchange.

H6: Shared language has a positive correlation with indirect benefit exchange.

\section{Knowledge exchange}

Modern organisations thrive on applying the specialised skills in possession of individual members of the organisation. Individuals with the desired knowledge usually command respect from their colleagues because their knowledge could be the life line of the organisation. This could be beneficial to the organisation and the individual who possesses the sort after knowledge. Molm (2010) classified the knowledge exchange benefit into bilateral and unilateral benefit, because some individuals would not mind sharing their knowledge even though they do not receive immediate and direct reciprocal knowledge from the same individual. Molm (2010) categorised direct knowledge exchange as either reciprocal exchange or negotiated exchange. Negotiated exchange represents a mutual flow of benefits with binding forms of exchange. In this type of exchange, the actors engage in a discussion to put terms of benefit exchange in place (Molm 1997). Reciprocal exchange, on the contrary, can have a series of unidirectional flows of benefit, with the exchange process built up from individual acts rather than a binding agreement between the actors.

Knowledge exchange can yield either direct or indirect exchange benefit. Unilateral exchange is explained through the theory of reciprocity, which is the process whereby one actor shares information without negotiating or knowing whether or when he or she is going to get any information in return. Molm (2010) used alphabets to represent actors in the sharing process, which is related to the explanation of Granovetter (1983) of the social network theory, whereby the first person may be actor $A$, the second person actor $B$ and the third person actor $C$. In short, actor $A$ sends information to actor $B$ without expecting to receive anything from actor $B$. Actor $A$ might be sharing because he or she has a lot of information or is kind-hearted, to name but a few.

Bilateral knowledge sharing is different from unilateral knowledge sharing in that it is a two-way street knowledge sharing process, whereby actor $A$ transfers knowledge to actor $B$ who, in turn, also transfers some knowledge to actor $A$. In this way, both participants benefit directly from each other. In indirect exchange, one actor gives benefits to another actor and receives benefits from another actor (but not from the same actor). Actor $A$ might provide information to actor $B$ who, in turn, provides information to $C$, while actor $C$ provides information to actor $A$, and actor $C$ does not have to know that $A$ is the originator of the shared benefit. In this way, actor $A$ benefits indirectly, as he or she is benefiting from another actor than actor $B$.

Reciprocity of knowledge within any type of community could be structured with formal rules that should be followed by the participants in the knowledge exchange. However, some communities of practice exchange knowledge in an informal and unstructured environment, especially where some kind of strong social ties exist (Granovetter 1983). Reciprocity that is based on a unilateral benefit is often found in circumstances where participants in the exchange process have strong social ties and the individuals have a favourable perception of their social identity with the community (Granovetter 1983; Molm 2010). Whereas, participants would expect bilateral benefit in circumstances where there is weak social ties in the community and reputation is not favourable (Granovetter 1983; Molm 2010). Participants who are brought together by weak ties have no affective commitment to one other, because their relationship could be limited to a specific project goal. Besides the project goal bond, they are bonded by contractual agreement to share knowledge to achieve the project goal.

H9: Direct and indirect benefit exchange are the same from the perspective of the UNISA students who are using social media for learning purposes.

\section{Social trust}

Trust is a universal concept that influences any sort of human engagement especially where contentious issues are concerned. Newton (2001) defined trust as the individual's belief that, at worst, other people will not harm him or her knowingly or willingly, and that he or she is going to act in his or her interest. Even though a number of factors have been proposed, Sharrat and Usoro (2003) and Mayer, Davis and Schoorman (1995) revealed three sources of social trust: benevolence, competence and integrity. Ability and competence are sometimes used interchangeably as the factor of social trust.

Benevolence is the extent to which one party is willing to do good to the other party involved without expecting to profit from sharing. Integrity is the trustor's perception that the trustee conforms to a set of standards that is acceptable to the trustor. Ability or competence is a group of skills and characteristics which allows an individual to have influence in a specific domain. They are important in social media interaction to ensure that everyone who is exposed to specialised knowledge would not exploit the knowledge in ways that would have a negative effect on the members of the community.

Participants who are brought together by weak ties are likely to judge fellow participants in the knowledge sharing exercise based on social trust factors until the ties become stronger. A decision to share knowledge is a result of perceived bilateral benefit if social trust does not exist. On the contrary, participants would expect a unilateral benefit 


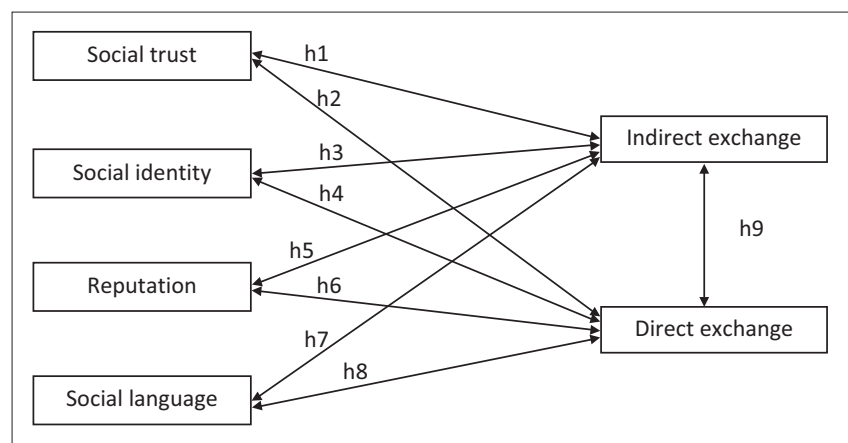

FIGURE 1: Theoretical framework for this study.

in the case of strong ties. Among the elements of social trust, competence is the determinant of strong or weak ties, because perceived competence is observable from a distant relationship.

H7: Social trust has a positive correlation with indirect benefit exchange.

H8: Social trust has a positive correlation with direct benefit exchange.

\section{Research methodology}

To answer the above research questions, the researchers had to choose an appropriate research design, which also helped to achieve the research objectives. A survey was chosen to allow researchers to gather the opinions of participants on the subject of investigation, especially where there is a wide population (Creswell 2012). In this study, the population consists of students who are registered only with the ODL University in South Africa. This university enrols more than 20000 students in any given year. Students are advised to have access to computers that are connected to the Internet at least once a week. However, it is compulsory for students registered for qualifications at the School of Computing to have regular access to a computer that is connected to the Internet, because of the nature of the courses offered by the school. A combination of theoretical and random sampling techniques was used to draw a sample that more likely would have used social media than those whose likelihood could not be ascertained by the researchers. We selected participants from the courses that incorporate social media platforms in the learning process. In the School of Computing, there are six courses that incorporate social media in the learning process. The average number of students registered for these courses is 397 . The theoretical aspect of the sampling informed the selection of students in the School of Computing.

In respect of this study, the selection of the survey was based on the ability to allow the researchers to gather the perceptions of participants who share knowledge on social media platforms. A questionnaire was used as instrument to collect data to evaluate the factors that influence the dimensions of reciprocity. The items in the questionnaire were formulated in a logical sequence, eliminating vague questions, and all the items and dimensions were meant to avoid instigating a biased view. The questionnaire comprised close-ended questions. Literature is instrumental in the extraction of scales, and each item was placed in a theoretical dimension. The items were measured using a Likert scale ranging from 1 to 5 points, with 1 representing strongly disagree and 5 representing strongly agree. The questionnaires were distributed to the sample by email. The researchers employed a random sampling technique to ensure that everybody had an equal chance of being selected for participation in the study. The sample was drawn from a population of UNISA students who had access to the Internet and have social media experience. These students were enrolled for various qualifications in the School of Computing. The researchers could reasonably expect these students to have access to social media, because Internet access was compulsory, the researchers do not imply that all those students with Internet access also had access to or used social media. The questionnaire was distributed to 315 students and 204 responses were received. The response rate is $65 \%$ of the sample. In the following section, data handling will be discussed.

\section{Discussion}

Once data had been collected, edited and coded, validity and reliability tests were performed to ensure that the data set at hand was in fact testing what it was meant to test; and the instrument would yield the same results if the study was replicated under similar circumstances. The first validity test was content validity, which had been done before the data collection during the development of the research instrument. A pilot study was conducted by distributing the instrument to academic staff members and students at the School of Computing. They were asked to complete the questionnaire and comment about readability, complexity and the length and grouping of items in each dimension. The comments were used to revise the structure and wording of the questionnaire, and then the questionnaire was distributed to the sample.

Based on the collected data set, the researchers performed an exploratory factor analysis (EFA) to test construct validity. The EFA, among others, was useful in ensuring that data items were loaded in the correct factors and were correlated with other items in the same factor. We used the maximum likelihood extraction method, the Promax rotation method with Kaiser normalisation. All items with a factor loading less than 0.3 were suppressed and not used in the next stage of the analysis. The results of the EFA yielded numerous measures that could be interpreted individually.

Among the other tests performed was sample adequacy through indication of a pattern of correlations that was relatively compact, thereby ensuring the EFA yields' distinct and reliable factors. We used the Kaiser-Meyer-Olkin (KMO) and Bartlett's test shown in Table 1. An acceptable KMO value should be greater than 0.5 , or closer to 1 so that the sample could be accepted as adequate for factor analysis. The result of the factor analysis yielded a KMO value equal to 0.845 , which falls within the meritorious range according to Hutcheson and Sofroniou (1999). The Bartlett's test of 
TABLE 1: The KMO and Bartlett's test.

\begin{tabular}{lll}
\hline Test & Measuring criteria & Results \\
\hline $\begin{array}{l}\text { Kaiser-Meyer-Olkin } \\
\text { measure of sampling }\end{array}$ & - & 0.845 \\
adequacy & & \\
$\begin{array}{l}\text { Bartlett's test of } \\
\text { sphericity }\end{array}$ & Approx. chi-square & 2579.552 \\
& $d f$ & 325 \\
& Sig. & 0.000 \\
\hline
\end{tabular}

Approx. chi-square, approximate chi-square; $d f$, degrees of freedom; Sig., significance.

sphericity enabled the researcher to test independence on the variable in the factor analysis in relation to the sample size. A significant chi-square in those factors are independent and make a unique contribution to the analysis (Field 2013). The results of Bartlett's test in Table 1 show that the chi-square is significant.

In addition to the results of the KMO and Bartlett's test, factor extraction yielded six factors and all extracted items have an eigenvalue greater than 0.4. Each factor has at least three items loaded to it. These factors account for $75 \%$ cumulative variance. Table 2 shows six loaded factors and a Cronbach's alpha for each factor. Following factor extraction, each factor was named in relation to the group of items that make up the specific factor. Theoretical sensitivity was useful in naming factors. As all the items were drawn from literature, it was appropriate for the researcher to refer back to the literature to name factors. Therefore, factor names are directly related to the theoretical construct used in the literature review of this study.

The codes in Table 2 were used during the coding process as they represent theoretical constructs, which are also in line with factor naming. The names for the codes are as follows: SOCID = social identity, RPTN = reputation, SOC_TRS = social trust, SHARLANG = shared language, DIR_EXC = direct exchange and INDIR_EXC = indirect exchange. At this point, the researcher gained a degree of confidence in the data set at hand since items in each factor actually tested what they were supposed to test, thereby confirming construct validity. EFA was performed on the data set that had been collected with an instrument, which had gone through content validity during the pilot study.

We performed a reliability test on a data set that had been subjected to content validity testing, to assess the replicability of similar results if the instrument is used in a similar study, using Cronbach's alpha among other techniques. According to Tavakol and Dennick (2011), an acceptable Cronbach's alpha should be above 0.6 , good above 0.7 and excellent above 0.8 , so the targeted value was above 0.6. Indirect exchange had the lowest value (0.738) compared with the other factors used in this analysis, but it is a good value. On the contrary, direct exchange had the highest values. Therefore, the data used in the analysis are reliable and valid.

\section{Correlation}

To achieve the research objectives, the researcher had to perform an analysis appropriate for the data set at hand and
TABLE 2: The factor extraction result, Cronbach's alpha, loading and standard deviation.

\begin{tabular}{lllllc}
\hline Constructs & $\begin{array}{l}\text { Cronbach's } \\
\text { alpha } \boldsymbol{\alpha}\end{array}$ & Items & Loading & Mean & $\begin{array}{c}\text { Standard } \\
\text { deviation }\end{array}$ \\
\hline $\begin{array}{l}\text { Direct benefit } \\
\text { exchange }\end{array}$ & 0.905 & DIR_EXC_1 & 0.770 & 3.47 & 1.138 \\
& & DIR_EXC_2 & 0.715 & 3.49 & 1.256 \\
Indirect & 0.738 & DIR_EXC_3 & 0.620 & 3.80 & 1.275 \\
benefit & & INDIR_EXC_1 & 0.838 & 4.14 & 1.083 \\
exchange & & INDIR_EXC_2 & 0.561 & 3.48 & 1.309 \\
& & INDIR_EXC_3 & 0.465 & 3.90 & 1.123 \\
Reputation & 0.742 & RPTN_1 & 0.916 & 3.04 & 1.130 \\
& & RPTN_2 & 0.811 & 2.95 & 1.192 \\
& & RPTN_3 & 0.622 & 2.86 & 1.258 \\
Shared & \multirow{2}{*}{0.878} & RPTN_4 & 0.549 & 2.89 & 1.228 \\
langauge & & SHARLANG_1 & 0.877 & 3.41 & 1.068 \\
& & SHARLANG_2 & 0.820 & 3.56 & 0.964 \\
Social & \multirow{2}{*}{0.763} & SHARLANG_3 & 0.427 & 3.36 & 0.976 \\
identity & & SOCID_1 & 0.865 & 3.03 & 1.266 \\
& & SOCID_2 & 0.824 & 2.92 & 1.199 \\
& & SOCID_3 & 0.734 & 3.34 & 1.231 \\
& & SOCID_4 & 0.724 & 3.67 & 1.242 \\
Social trust & 0.742 & SOC_TRS_1 & 0.962 & 2.94 & 1.264 \\
& & SOC_TRS_2 & 0.870 & 2.83 & 1.149 \\
& & SOC_TRS_3 & 0.630 & 2.72 & 1.159 \\
\hline
\end{tabular}

SOCID, social identity; RPTN, reputation; SOC TRS, social trust; SHARLANG, shared language; DIR_EXC, direct exchange; INDIR_EXC, indirect exchange.

also had to test the hypotheses. The hypotheses are outlined in the theoretical framework and involve evaluation of correlation between independent and dependent variables. To evaluate association, the researchers will use a correlation coefficient to assess the significance of the R-value. A strong correlation is represented by a coefficient that is closer to 1 depending on the direction of the correlation, whereas a weak coefficient is represented by 0 . Table 3 shows a correlation matrix that includes all variables for testing the hypotheses. A correlation coefficient that stands out is between reputation and social identity, which is not helpful in this case because it is an indication of multiple collinearity among independent variables. This means that these two variables cannot be used to perform regression analysis. It is important to note the weak and insignificant correlation coefficient between indirect and direct exchange benefit, because it shows that there is no collinearity between these variables. Each one is testing a different factor.

The strong correlation between reputation and social identity confirms theoretical observation where individuals who have a good reputation are likely to be accepted, and they share a social identity with the community. Table 3 also shows that the correlation between reputation and direct exchange is better than the correlation between reputation and indirect exchange. This could mean that the individual who is sharing knowledge is more likely to share it directly with the next person if the other person's reputation is good.

The correlation evaluation shown in the correlation matrix reveals that $\mathrm{H} 1$ is confirmed because the correlation between indirect benefit exchange and social trust is significant and positive, but weak with an $R$-value which is equal to 0.201 . Conversely, the correlation between direct benefit exchange and social trust is insignificant, therefore, $\mathrm{H} 2$ is rejected. 
TABLE 3: Correlation coefficients matrix.

\begin{tabular}{|c|c|c|c|c|c|c|c|}
\hline Correlations & Test & 1 & 2 & 3 & 4 & 5 & 6 \\
\hline \multirow[t]{3}{*}{ Direct exchange } & Pearson correlation & 1 & - & - & - & - & - \\
\hline & Sig. (two-tailed) & - & - & - & - & - & - \\
\hline & $N$ & 206 & - & - & - & - & - \\
\hline \multirow[t]{3}{*}{ Indirect exchange } & Pearson correlation & 0.076 & 1 & - & - & - & - \\
\hline & Sig. (two-tailed) & 0.280 & - & - & - & - & - \\
\hline & $N$ & 206 & 206 & - & - & - & - \\
\hline Reputation & Pearson correlation & $0.308 * *$ & $0.213^{* *}$ & 1 & - & - & - \\
\hline & Sig. (two-tailed) & 0.000 & 0.002 & - & - & - & - \\
\hline & $N$ & 206 & 206 & 206 & - & - & - \\
\hline \multirow[t]{3}{*}{ Social identity } & Pearson correlation & 0.127 & $0.166 *$ & $0.624 * *$ & 1 & - & - \\
\hline & Sig. (two-tailed) & 0.068 & 0.017 & 0.000 & - & - & - \\
\hline & $N$ & 206 & 206 & 206 & 206 & - & - \\
\hline \multirow[t]{2}{*}{ Social language } & Pearson correlation & $0.240 * *$ & $0.284 * *$ & $0.445 * *$ & $0.469 * *$ & 1 & - \\
\hline & Sig. (two-tailed) & 0.001 & 0.000 & 0.000 & 0.000 & - & - \\
\hline \multirow[t]{3}{*}{ Social trust } & Pearson correlation & 0.108 & $0.201 * *$ & $0.470 * *$ & $0.588 * *$ & $0.261 * *$ & 1 \\
\hline & Sig. (two-tailed) & 0.122 & 0.004 & 0.000 & 0.000 & 0.000 & - \\
\hline & $N$ & 206 & 206 & 206 & 206 & 206 & 206 \\
\hline
\end{tabular}

*, correlation is significant at the 0.05 level (two-tailed); ${ }^{*}$, correlation is significant at the 0.01 level (two-tailed).

It is notable that the correlation between direct exchange and social identity is weak, positive and insignificant. This leads to the rejection of $\mathrm{H} 3$. However, the correlation between social identity and indirect benefit exchange is significant ( $p=0.017)$, weak correlation $(R=0.166)$ and positive, so $\mathrm{H} 4$ is confirmed.

The association between reputation and indirect benefit exchange is positive, and significant with an $R$-value which is equal to 0.0.213 and a $p$-value which is equal to 0.000 . Similarly, the association between reputation and direct benefit exchange is positive and significant with an $R$-value which is equal to 0.308 and a $p$-value which is equal to 0.017 . Therefore, $\mathrm{H} 5$ and $\mathrm{H} 6$ are confirmed.

Social language is positively and significantly associated with indirect benefit exchange, yielding an $R$-value which is equal to 0.284 and a $p$-value which is equal to 0.001 . The association of social language and direct benefit exchange is also positive and significant yielding an $R$-value which is equal to 0.240 and a $p$-value which is equal to 0.000 . Therefore, the $\mathrm{H} 7$ and $\mathrm{H} 8$ are confirmed.

In addition to the correlation test, the researcher performed a test of means difference between indirect and direct benefit exchange, using a $t$-test. The results indicate that the variance between the indirect and direct benefit of exchange is significant with a $t$-value and $p$-value that are equal to 0.000 . The researcher compared the $t$-value with the critical value, using a degree of freedom and $p$-value. Therefore, H9 is rejected.

In summary, Table 3 shows that only social language and reputation have a positive and significant correlation with direct and indirect benefit exchange, while the rest of the factors have a positive and significant correlation with direct or indirect benefit exchange. In addition to that, all factors that have some correlation with at least direct or indirect

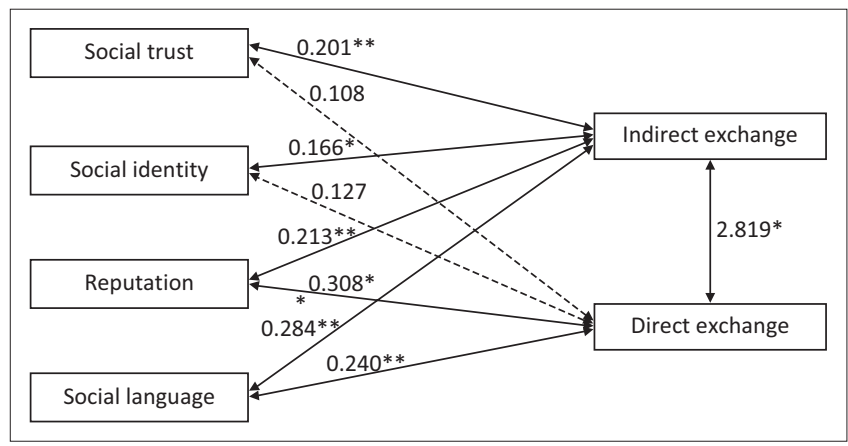

*, correlation is significant at the 0.05 level (two-tailed); **, correlation is significant at the 0.01 level (two-tailed).

FIGURE 2: Variable correlations after testing the hypotheses.

benefit exchange, and there is no collinearity between direct and indirect benefit exchange.

The results reveal that indirect and direct benefit exchange are not correlated and are indeed perceived as variables that are independent from each other. Some students share their knowledge on social media platforms with the expectation of direct exchange of benefit from their knowledge sharing partners. Although the sharing of knowledge via social media is not driven by the expectation of direct exchange of benefit from sharing partners, they hope that they will gain knowledge from others whenever they need it.

The above results also show that some of the independent variables are only in correlation to direct or indirect benefit exchange. This is in line with the fact that indirect and direct benefit exchange are, in the current circumstances, independent of each other.

\section{Theoretical or practical contribution of the study}

Based on the above results, conclusion can be drawn that the study contributes to the development of a social mediadelivered instructional design. The instructional designer 
in an ODL institution should take note of the fact that some students engage in collaborative activities by means of social media with the expectation of direct reciprocal benefit from fellow students while others do not mind to collaborate without expecting direct benefit exchange from fellow students.

It is important for an instructional designer to note that social trust, reputation, social language and social identity do not have similar correlations to the indirect and direct benefit exchange variables. Social language and reputation are correlated with direct and indirect benefit exchange; however, social trust and social identity have positive and significant correlation with only indirect benefit exchange. This could mean that where student engagement is in a controlled learning environment with direct engagement, the students would not be worried about social identity and social trust.

Conversely, where the instructional designer requires uncontrolled engagement and indirect exchange of benefit, the students would be concerned about social identity and social trust of their fellow collaborators on the social media platform. In such learning environments, sharing knowledge is discretionary, and knowledge agents would be comfortable with sharing knowledge with someone with whom they share some sense of social belonging. Students start opening up when they believe in the competence of their fellow students in the subject matter (benevolence and integrity) which would otherwise not be a concern in a controlled environment.

\section{Limitations of the study and future research}

This study covered a sample of students who are drawn together by the fact that they are registered for the same qualification. This could have eliminated the effect of relational aspects in the sample. The researcher did not test the relational factor because students in an ODL institution are bound by academic goals rather than social relational bonds.

In future studies, the researcher will test the relational dimension of social capital to evaluate the impact of strong ties and weak ties on decisions to share and motivations of benefit exchange. The envisaged future study will cover a wider population to include students in residential and open, distance and e-learning (ODEL) institutions around Johannesburg, South Africa.

\section{Conclusion}

The researcher set out to test the hypotheses outlined in the theoretical framework section of this study and achieved the research objectives of the study. To test the hypotheses, a survey research design was employed so that the researcher could gather as many responses as possible from the sample.

Data analysis techniques were chosen with the aim of achieving the research objectives, and the most appropriate data analysis technique is correlation. It allows for derivation of inferences for the data to the whole research population. The results reveal that social identity and social trust should only be taken into account when developing a social media-based instructional design that will be delivered in an uncontrolled environment, where students expect indirect benefit exchange. On the contrary, all other variables are influential to both indirect and direct benefit exchange.

\section{Acknowledgements Competing interests}

The authors declare that they have no financial or personal relationships that may have inappropriately influenced them in writing this article.

\section{Authors' contributions}

P.L.M. was involved in writing of abstract, introduction, background, research objectives, methodology, discussion of results, contribution of the study, limitations of the study and future research, and conclusion. L.S.N. was involved in writing of abstract, literature review and references. Both were responsible for overall proofreading and editing of the article.

\section{References}

Chiu, C.M., Hsu, M.H. \& Wang, E.T.G., 2006, 'Understanding knowledge sharing in virtual communities: An integration of social capital and social cognitive theories', Decision Support Systems 42(3), 1872-1888. https://doi.org/10.1016/j.dss. Decision Suppo

Crane, L., 2012, 'Trust me, I'm an expert: Identity construction and knowledge sharing', Journal of Knowledge Management 16(3), 448-460. https://doi. org/10.1108/13673271211238760

Creswell, J.W., 2012, Qualitative inquiry and research design: Choosing among five approaches, Sage, Los Angeles, CA.

Dench, S., Hurstfield, J., Hill, D. \& Akroyd, K., 2006, 'Employers' use of migrant labour: Summary report', Home Office Online Report $03 / 06$.

Dimofte, C.V., Goodstein, R.C. \& Brumbaugh, A.M., 2015, 'A Social identity perspective on aspirational advertising: Implicit threats to collective self-esteem and strategies to overcome them', Journal of Consumer Psychology 25(3), 416-430. https://doi. org $/ 10.1016 / \mathrm{j}$.jcps.2014.12.001

Field, A., 2013, Discovering statistics using IBM SPSS statistics, Sage, London.

Granovetter, M., 1983, 'The strength of weak ties: A network theory revisited', Social structure and network analysis 1(1983), 105-130.

Hogg, M.A. \& Terry, D.J., 2000, 'Social identity and self-categorization processes in organizational contexts', Academy of Management Review 25(1), 121-140.

Hutcheson, G. \& Sofroniou, N., 1999, The multivariate social science scientist: Statistics using generalized linear models, Sage, Thousand Oaks, CA.

Kimmerle, J., Wodzicki, K. \& Cress, U., 2008, 'The social psychology of knowledge management', Team Performance Management 14(7/8), 381-401.

Koskinen, K.U., 2005, 'Metaphoric boundary objects as co-ordinating mechanisms in the knowledge sharing of innovation processes', European Journal of Innovation Management 8(3), 323-335. https://doi.org/10.1108/14601060510610180

Li, Y. \& Sheldon, P., 2010, 'HRM lives inside and outside the firm: Employers, skill shortages and the local labour market in China', The International Journal of Human Resource Management 21(12), 2173-2193. https://doi.org/10.1080/0958 5192.2010.509623

Liu, K.-L, Chang, C.-C. \& Hu, I.-L., 2010, 'Exploring the effects of task characteristics on knowledge sharing in libraries', Library Review 59(6), 455-468. https://doi. org/10.1108/00242531011053968

Ma, Z. \& Yu, K.-H., 2010, 'Research paradigms of contemporary knowledge management studies: 1998-2007', Journal of Knowledge Management 14(2), 175-189. https://doi.org/10.1108/13673271011032337

Mayer, R.C., Davis, J.H. \& Schoorman, F.D., 1995, 'An integrative model of organizational trust', Academy of Management Review 20(3), 709-734.

Mehra, A., Dixon, A.L. \& Brass, D.J., 2006, 'The social network ties of group leaders: Implications for group performance and leader reputation', Organizational Science 17(1), 64-79. https://doi.org/10.1287/orsc.1050.0158 
Molm, L.D., 1997, Coercive power in social exchange, Cambridge University Press, Cambridge, UK.

Molm, L.D., 2010, 'The structure of reciprocity', Social Psychology Quarterly 73(2), 119-131. https://doi.org/10.1177/0190272510369079

Nahapiet, J., 1998, 'Social capital, intellectual capital and the organizational advantage', Academy of Management Review 23(2), 242-266.

Newton, K., 2001, 'Trust, social capital, civil society, and democracy', International Political Science Review 22(2), 201-214. https://doi.org/10.1177/0192512101222004

Pi, S.M., Chou, C.H. \& Liao, H.L., 2013, 'A study of Facebook groups members' knowledge sharing', Computers in Human Behavior 29(5), 1971-1979. https://doi. org/10.1016/j.chb.2013.04.019

Redding, G. \& Rowley, C., 2012, 'Methodology challenges in the study of social capital in Asia', in D.D. Berg, D.J. Ketchen, \& C.L. Wang, (eds.), West meets East: Building Theoretical Bridges, pp. 265-287, Emerald, London.

Riketta, M. \& Van Dick, R., 2005. 'Foci of attachment in organizations: A meta-analytic comparison of the strength and correlates of workgroup versus organizational identification and commitment', Journal of Vocational Behavior 67(3), 490-510. https://doi.org/10.1016/j.jvb.2004.06.001

Sharrat, M. \& Usoro, A., 2003, 'Understanding knowledge sharing in online communities of practice', Electronic Journal on Knowledge Management 1(2), 187-196.
Tajfel, H., 1972, 'Social categorization (English translation of "La cat6gorisation Sociale")', Introduction ala Psychologie Sociale 1, 272-302.

Tajfel, H. \& Turner, J.C., 1985, The social identity theory of intergroup behavior in psychology of intergroup relations, Nelson-Hall, Chicago, IL.

Tavakol, M. \& Dennick, R., 2011, 'Making sense of Cronbach's alpha', Internationa Journal of Medical Education 2, 53-55. https://doi.org/10.5116/ ijme.4dfb.8dfd

Tolman, E.C., 1943. Identification and the post-war world, The Journal of Abnorma and Social Psychology 38(2), 141-162.

Tsai, W. \& Ghoshal, S., 1998, 'Social capital and value creation: The role of intrafirm networks', Academy of Management Journal 41(4), 464-476. https://doi. org $/ 10.2307 / 257085$

Wang, S. \& Noe, R.A., 2010, 'Knowledge sharing: A review and directions for future research', Human Resource Management Review 20(2), 115-131. https://doi org/10.1016/j.hrmr.2009.10.001

World Wide Worx, 2013, 'Social media: Addiction and boon to students', viewed 20 November 2015, from http://www.worldwideworx.com/

Zhuang, Y., Fong, S. \& Shi, M., 2008, 'Knowledge-empowered automated negotiation system for e-Commerce', Knowledge and Information Systems 17(2), 167-191. https://doi.org/10.1007/s10115-007-0119-x 